\title{
Dissemination of Consumer Law and Policy in Africa, Asia, the Americas, and Australia
}

\author{
Hans W. Micklitz ${ }^{1} \cdot$ Geraint Howells $^{2} \cdot$ Claudia Lima Marques $^{3} \cdot$ Tjakie Naude $^{4}$ \\ Published online: 5 November 2018 \\ C Springer Science+Business Media, LLC, part of Springer Nature 2018
}

There is not much, if any, research available on consumer law and policy outside Australia, the European Union (EU), the United States (US), and in limits South America and India, ${ }^{1}$ and what little there is has hitherto been limited. This gap needs to be closed through focused research on consumer law in Africa, Asia, and South America, as well as its interaction with Australian, European, and US American consumer law and policy. Steps towards filling this gap are taken as part of a much broader project financed by the Academy of Finland on the "External Dimension of European Private Law." ${ }^{, 2}$ With regard to consumer law, we (Geraint Howells (Asia), Claudia Lima Marques (South America), Tjakie Naude (Africa), and Hans Micklitz (EU)) have joined forces with the European University Institute, Helsinki University, and the Journal of Consumer Policy. All three institutions have generously contributed funding for research into African, Asian, and South American consumer law.

One of the major challenges was to make scholarship from such different regions of the world accessible and, boldly spoken, suitable for comparison. At the outset, we decided to organize a series of conferences in Hong Kong, Cape Town (South Africa), and Porto Alegre (Brazil) in 2017. Organizing conferences in these locations made it much easier to assemble scholars from each continent. This would have been impossible and unaffordable, had we decided to invite experts from these continents to, e.g., Florence or Helsinki. Overcoming this organizational hurdle was crucial. Having done so, we decided to facilitate discussion and comparison through developing a uniform template, built around three major issues: (1) the general features, (2) case studies, and (3) external influences. This template has been designed

\footnotetext{
${ }^{1}$ Micklitz, H. and Twigg-Flesner, C. (2010). Editorial: Think global-Towards international consumer law. Journal of Consumer Policy, 33, 201-207.

${ }^{2}$ Distinguished as research of scientific excellence, the project receives funding under the Finland Distinguished Professor (FiDiPro) funding programme http://www.helsinki.fi/katti/english/FiDiPro_project.htm
}

Hans W. Micklitz

Hans.Micklitz@EUI.eu

1 European University Institute, 50014 Fiesole, FI, Italy

2 City University of Hong Kong, Hong Kong, Hong Kong

3 Universidade Federal do Rio Grande do Sul, Porto Alegre, Brazil

4 University of Cape Town, Cape Town, South Africa 
to provide guidance and to create a knowledge base for further research. This template is reprinted below in the form it was made available to all the participants.

The 40th anniversary of the Journal of Consumer Policy, celebrated at the EUI in Florence in 2018, was a wonderful opportunity to start a deeper debate about the interaction of the different regions, the differences and similarities, and the outlook of a truly international consumer law that deserves this label. Such a consumer law had to bring together the legal culture and traditions from all over the world and needs to overcome the still dominating Western (EU/US) biased outlook of consumer law.

Revised papers from each of the four conferences will be published separately. Those presented at the Hong Kong conference will be published in a book edited by Mateja Durovic, Geraint Howells, André Janssen, and Hans-W. Micklitz (Consumer Protection in Asia-Past, Present and Future (CUP)), whilst the papers presented at Cape Town and Porto Alegre will feature in two Special Issues of the Journal of Consumer Policy: Cape Town in this issue and Porto Alegre in 2019 or 2020 . The overall findings on the comparability of the regions and the outlook of international consumer law will be published in the Journal of Consumer Policy.

This Special Issue is the first of four publications, dealing with the situation in Anglophone Africa. The contributions have been presented in Cape Town, discussed widely, and amended in the review procedure. Special thanks go Tjakie Naude, without whose relentless involvement neither the conference nor the special issue could have been realized.

\section{The Common Template}

\section{General Characteristics of Consumer Law in Each Jurisdiction}

Broadly describe the principal legal framework for consumer protection in your country. Is there a separate and independent statute on consumer protection? Or is your consumer protection regime situated in different statutes and/or contained in codes such as a civil code or in uncodified common law? Is there a national consumer policy?

Does your country's consumer law consist of what could be called first generation consumer law as well as what could be called second generation consumer law?

- Please understand the following as a kind of general background to explain our understanding.

First generation consumer law is based on the four basic consumer rights as set out in the declaration of President Kennedy in 1962 (right to safety, to be informed, to choose, and to be heard). The overall idea of first generation consumer laws is to have general rules that apply to all sorts of commercial activities, although the implicit blueprint is more often than not the contract of sales. Examples of first generation consumer laws are the control of unfair terms in standard contracts (boilerplate contracts), the control of unfair and misleading commercial practices (including misleading advertising), product liability claims against producers, importers, distributors and retailers, rules on quality of goods sold, and the action for injunctions (interdicts).

The second generation of consumer law very much focuses on contracts for service, on telecommunication, energy, transport, and financial services. The so-called servicification of goods through digitalization enhances the key role of services. On the surface, what can be observed is a fragmentation and compartmentalization of consumer law. Each of the sectors could be regarded as 
a silo, in which consumer law is regulated from cradle to grave from the making of consumer rules to the enforcement via Alternative Dispute Resolution Mechanisms (such as sectoral ombuds). It will have to be tested what role remains for general contract law. Standardization, i.e., nonlegislative norms established by private bodies or regulators is key. Technical standards, which affect the rights and duties of the parties, are developed outside established international organizations in fora where private parties, big companies, governments and agencies are co-operating.

II. Three Case Studies on Product Liability, Consumer Products, and Telecommunication Services

The project has to narrow down the type of questions to be investigated. Unfair terms legislation and unfair commercial practices cut across the three areas. They form the fundament on which we have designed three cases studies. The questions are meant as a source of inspiration. It would remain for the reporter to find answers.

- The first category to be investigated is product liability and product safety, for the simple reason that these are extremely important consumer policy issues around the world. Take the example of furniture which is found to be dangerous because it uses foam that is inflammable. A sofa catches fire and injures a family and their belongings, including a 3D printer they use for a small home business.

- Where do you find the relevant safety standards? Are there specific rules for furniture? Is there a general safety requirement? What role does standardization and conformity assessment play? Can these rules affect the labelling of products (e.g., to indicate any flammability risks)?

- Which body is responsible for enforcing safety standards? What actions can they take against producers and suppliers (e.g., product bans, require withdrawal from the market)? Can any steps be taken to deal with products that are in the hands of end consumers? What about if the product has been imported to your country? Is the importer liable?

- What remedies would there be to recover for the personal injury and damaged property?

- What is the impact of advertising on the remedies in case the safety of the product has been advertised? Does a potentially misleading advertising affect liability claims?

- The second category deals with consumer products. A typical example would be refrigerators as they are needed everywhere around the world. What happens if the refrigerator is defective? Who is responsible? The seller or the manufacturer or both? What place is there for guarantees from the manufacturer? In what way is an eventual commercial guarantee (contractual warranty given by the manufacturer or seller) different from mandatory legal guarantees provided for in consumer law? So the study would have to deal with consumer sales law, with the law on the control of standard terms and with the control of unfair commercial practices, as the latter overlap in handling commercial guarantees. For instance, we might think of the European cases on Apple products where the relationship between the supplier's commercial guarantee and the mandatory legal warranty was unclear and potentially misleading.

- What are the consumer's rights if the delivery is delayed? What is the position if the consumer pays for the goods in the shop and the shopkeeper arranges delivery but the refrigerator is damaged in transit?

- The third issue concerns telecommunication. Mobile phones have opened up new opportunities for all consumers around the world. Quite often, they are not sold or 
bought at a realistic price but are offered to the consumer in connection with a twoyear service contract. So there is a product and a service or a combination of services offered by the service provider. Sometimes, consumers use the mobile phone to conclude other agreements such as credit agreements. Here, the mobile turns into the catch all device, as a communication means but also as a means to conclude contracts. This may cause problems as the resultant contract is not in writing and not much information may be given to the consumer about the contract. It may be that consumers run into difficulties if they finance the mobile or the contract via credits that are sold and accepted via the mobile phone. Telecom service contracts are a rather new and dynamic field. We want to find out what issues are causing consumers problems in your country and the law's response. The following should therefore be understood as a source of inspiration and guidance. Please include what is most relevant for your country. Mention of whether these are addressed by regulation or courts would be helpful.

- Please consider the following questions and explain whether there are remedies:

(1) Are long-term agreements automatically prolonged? Is that legal? Can the consumer cancel the contract, i.e., if he wants to move elsewhere? Can the consumer switch to another supplier and if so who pays for the switching? Is there a timeline in which the switching should be executed?

(2) Tied agreements: Can the consumer refuse payment to the telephone operator (telecommunications company providing the service) if the mobile is defective and does not work? What is the liability of the manufacturer of the phone and the telephone operator respectively in such a situation?

(3) Credit financed agreements: Is it admissible to conclude long tie agreements via SMS/WhatsApp etc.? Are there any safeguards-a written contract that must be supplied to the consumer, a right to withdrawal?

(4) Marketing of additional services: What can the consumer do to reject services he does not want to have in addition (ring tones, premium services and the like)? Can the services be imposed on consumers without their express consent or are there any protective measures?

It should therefore also be considered how the legal rules relating to each of the three sectors actually work in practice.

Consider the questions raised above in light of the further questions listed in the next rubric.

III. Interaction Between Consumer Law in Your Country and Foreign/Supranational Laws and Agencies

What interaction has there been between consumer law in your country and the consumer laws or policies of other countries or supranational bodies (such as the EU, the United Nations (UN) and Commonwealth Telecommunications Organization (CTO), World Bank, Organization for Economic Cooperation and Development (OECD))? Has there been a borrowing of ideas from other legal systems? Which foreign system has had the most impact? Has your country's consumer law influenced the law of other countries, whether within the immediate region or beyond? Is there an impact on trade agreements? The focus will be on the three areas identified above in part II. 
Is there some influence of foreign countries or supra-national bodies in the application of the laws or regulatory systems in practice? Case studies may be illuminating here.

To answer these broad questions, the project turns firstly to consider the influence of EU Consumer law and policy.

\section{Influence of EU Consumer Law and Policy}

Does your country have a bilateral or multilateral trade agreement or economic partnership agreement with the EU? If so, does this agreement contain any rules/policy requirements on consumer protection and if so, what is this policy? Has this policy made a difference to the substance and enforcement of consumer law in your country?

If your country does not have such an agreement with the EU, is there any other evidence of an external policy of the EU relating to consumer protection in your country?

If there is no broad policy on consumer protection in a trade agreement with the EU, is there a more sector-specific EU policy towards consumer protection in your country, which has impacted on consumer law and/or enforcement thereof? Focus particularly on the three sectors mentioned above (product safety, the telecommunication sector, including mobile or phone contracting, and consumer sales law more generally).

Is there other evidence of cooperation between the EU on the one hand and, on the other, the government, regulatory authorities, courts, agencies, technical bodies or consumer organizations in your country in respect of consumer protection in any of the three fields? Is there something like a dialogue?

Did your country use EU law as a model for the making of consumer law in your country in any of the three fields?

\section{Influence of Other Foreign and Supranational Laws and Policy}

Also consider the influence of relevant laws and policy of other states or supra-national organizations than the European Union in light of the same questions (in the previous part above).

For example, you could consider whether there are links between the US Federal Trade Commission (FTC) or United States Agency for International Development (USAID) on the one hand, and regulators, agencies, or technical bodies in your country on the other hand, and how this impacts on the substance and enforcement of consumer law in the three fields listed above. Has any practical impact on your law or enforcement resulted from your country's participation in the African Consumer Protection Dialogue (in which the FTC also plays a part)?

For example, what influence has Australian, English, and USA law or policy had on your consumer law and practice in the three fields?

For example, what influence has your consumer law and/or practice had on other countries? To what extent has your country had an impact on the dialogues on regulation that may take place at supra-national level? Have the UN Guidelines on Consumer Protection played a role in developing your policy.

If your consumer law and practice has not been influenced much by foreign or supranational law, you could use this opportunity to make a comparison between your law and practice and that of any foreign country or supranational body in relation to the three fields, in order to conclude whether either system could be improved. 